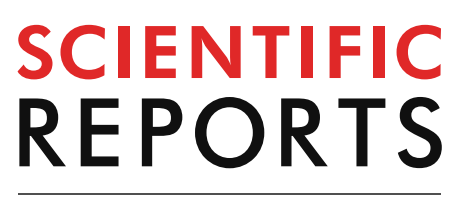

natureresearch

Check for updates

\title{
Thermal energy storage
} and thermal conductivity properties of fatty acid/fatty acid-grafted-CNTs and fatty acid/ CNTs as novel composite phase change materials

\author{
Amir Al-Ahmed ${ }^{1 凶}$, Ahmet Sarı ${ }^{1,2}$, Mohammad Abu Jafar Mazumder ${ }^{3}$, Billel Salhi ${ }^{1}$, \\ Gökhan Hekimoğlư ${ }^{2}$, Fahad A. Al-Sulaiman ${ }^{1} \&$ Inamuddin $^{4 凶}$
}

In recent year, fatty acids (FAs) are heavily studied for heat storage applications and they have shown promising advantages over other organic phase change materials (PCMs). Among the FAs; capric, palmitic and stearic acids are the most studied PCMs. Several researchers have investigated these FAs and tried to improve their thermal properties, mainly by adding different high conducting fillers, such as graphite, metal foams, CNTs, graphene etc. In most cases, these fillers improved the thermal conductivity and heat transfer property but reduce the heat storage capacity considerably. These composites also lose the mixing uniformity during the charging and discharging process. To overcome these issues, selected FAs were grafted on the functionalized CNT surfaces and used as conductive fillers to prepare FA based composite PCMs. This process significantly contributed to prevent the drastic reduction of the overall heat storage capacity and also showed better dispersion in both solid and liquid state. Thermal cycling test showed the variations in the thermal energy storage values of all composite PCMs, however, within the tolerable grade and they had appreciable phase change stability and good chemical stability even after 2,000 cycles.

Utilization of heat energy using phase change materials (PCMs) is an economical and environment friendly approach ${ }^{1}$. Among the different PCMs, there is a long list of organic compounds which have been studied for latent heat thermal energy storage (LHTES) ${ }^{2,3}$. These PCMs do not suffer from super cooling, they are chemically stable, and possess non-toxic/non-corrosive characteristics ${ }^{2}$. Among the organic PCMs, fatty acids (FAs) are extensively studied in recent years, due to their several superior properties over the other organic PCMs, such as, melting congruency, good chemical stability, nontoxicity, suitable melting temperature range and remarkable latent heat capacity (LHC) for solar passive heating applications ${ }^{4,5}$. Like all other organic PCMs, FAs also suffer from low thermal conductivity (TC) and leakage issue, if not properly housed. Easy and cheaper solution is the composite formation with suitable filler. A suitable filler based composite can enhance the heat conduction ability, and at the same time can provide stable form i.e. housing of the FAs. In a form-stable structure, we can avoid additional cost of encapsulation and can have wide dimensional flexibility. Different conductive

\footnotetext{
${ }^{1}$ Center of Research Excellence in Renewable Energy (CoRERE), King Fahd University of Petroleum \& Minerals, Dhahran 31261, Saudi Arabia. ${ }^{2}$ Department of Metallurgical and Material Engineering, Karadeniz Technical University, 61080 Trabzon, Turkey. ${ }^{3}$ Chemistry Department, King Fahd University of Petroleum \& Minerals, Dhahran 31261, Saudi Arabia. ${ }^{4}$ Advanced Functional Materials Laboratory, Department of Applied Chemistry, Faculty of Engineering and Technology, Aligarh Muslim University, Aligarh 202 002, India. ${ }^{\square}$ email: aalahmed@ kfupm.edu.sa
} 
filler have been tried ${ }^{6,7}$, however multiwall carbon nanotubes (MWCNTs here termed as CNTs only) are the favourite for TC enhancement of organic PCMs due to their excellent thermal and mechanical properties and stability $^{8-11}$. Recently, Yadav et al. ${ }^{12}$ studied capric acid (CA) mixed with three different $(0.01,0.02$ and 0.025$)$ volume \% of CNTs, and evaluated their thermo-physical parameters using T-history method. Among these three composites, $0.02 \mathrm{vol} \%$ of CNTs containing samples were found to be the best composition in terms of storage enthalpy, thermal cycling and stability. Liu et al. ${ }^{13}$ prepared a shape stabilized phase change material (SSPCM) by impregnating CA and CNTs within the fly ash. The composite sample showed much lower latent heat capacity as compare to that of the pure CA but it was comparable with the other reported CA based composite PCMs ${ }^{13}$. However, the heat transfer efficiency of the composite samples was found to be much higher than that of pure CA. In another study, Yang et al. ${ }^{14}$ prepared composite PCMs with different CNT contents (2, 6 and 10 wt\%). Like all other previous studies, the latent heat capacity decreases with the increasing amount of CNTs but the TC increases, so do the heat release rate.

The addition of pure carbon-based nano fillers to organic PCMs was responsible for the non-homogenous dispersion, which ultimately influence all thermal features of the final composite. Another issue was observed that the LHC of the PCM decreases with the increasing amount of carbon fillers, however the TC increases. Li et al. ${ }^{15}$ impregnated stearic acid (SA) within acid treated CNTs in different wt\%. Composite samples showed a great reduction in melting/freezing temperature of SA due to the interface confinement effect. However, its melting LHC was decreased with the increasing the amount of CNTs. Wang et al. ${ }^{16,17}$ modified CNTs by four different methods, namely, acid oxidation, mechano-chemical reaction, ball milling and grafting following acid oxidation. The modified CNTs were then mixed with palmitic acid (PA), and ultra-sonicated to get homogeneous distribution. It was observed that the latent heat of the composite PCM decreases with the increasing amount of CNTs, but again the TC increases. TC was found to be $51.6 \%$ higher with the addition of only 1 wt $\%$ of CNTs. In another work, the same research group ${ }^{18}$ also grafted oleylamine and octanol on the acid treated CNTs and used as a filler to prepare paraffin wax/CNTs composite PCMs. They showed that the latent heat capacity of the composite PCMs was also decreased with the increasing amount of CNTs, but TC increases. Moreover, the octanol grafted CNTs based composites showed higher TC values compare to that of oleylamine grafted CNTs based composites. Ji et al. ${ }^{19}$ used acid treated CNTs and pyrogallo absorbed CNTs to prepare composite PCMs with PA, and observed similar trend, the thermal conductivity increases with the increasing amount of the filers. Xiao et al. ${ }^{20}$ dispersed CNTs, oxidized CNTs and grafted CNTs into PA at a mass ratio of 1:100. The LHC of PA/G-CNTs were found to be exceeded that of pure PA and showed a higher TC. Shen et al. ${ }^{21}$ modify multi-walled CNTs and dispersed them into erythritol as PCM. They observed that this treatment improved the dispersion of CNTs in the melted PCM and TC value of the PCM was significantly boosted by adding $1.0 \mathrm{wt} \%$ CNTs. Li et al. ${ }^{22}$ grafted CNTs with octanol, tetradecyl alchohol and stearyl alcohol and then added to paraffin. The results demonstrated that the dispersion ability of grafted CNTs was better than CNTs and the TC of the grafted CNTs/paraffin composite PCMs was relatively higher than that of CNTs/paraffin.

As seen from the above summarized literatures that only in few studies modified/or grafted CNTs were used to improve the thermal properties of the FAs by minimizing the agglomeration problem of CNTs. However, the effect of the grafting amount of CNTs on the LHTES, cycling thermal reliability and thermal degradation stability as well as the TC of FAs were not investigated. With this sense, in the present work, three major FAs commonly used as PCM, namely capric, palmitic and stearic acids (CA, PA and SA) were selected. As different from the literature, these FAs were grafted on the functionalized CNTs (CNTs- $g$-FA) in three different grafting ratios and then the grafted CNTs were added to the FAs in ratio of $5 \mathrm{wt} \%$ to achieve thermally enhanced composite PCMs. For comparison, a composite of FAs with non-grafted CNTs additive in the same weight amounts was also prepared. The prepared FA/CNTs- $g$-FA and FA/CNTs composite PCMs were characterized and evaluated for morphology, distortional homogeneity and thermal properties. The obtained results were compared systematically to exhibit the effects of the grafted and non-grafted CNTs additives on the dispersion stability, phase change temperatures/LHC properties, TC values, cycling thermal/chemical stability and high thermal degradation temperatures of the FAs. The findings indicated that the FAs doped with CNTs- $g$-FA additives had better dispersion stability (both solid and melted state), higher LHC and TC values compared to FA/CNTs composites.

\section{Experimental}

Materials. Capric acid (CA; purity degree: $\geq 98 \%$; melting point: $27-32{ }^{\circ} \mathrm{C}$ ), palmitic acid (PA; purity degree: $\geq 98 \%$; melting point: $62-65{ }^{\circ} \mathrm{C}$ ) and stearic acid (SA; purity degree: $\geq 98 \%$; melting point: $67-72{ }^{\circ} \mathrm{C}$ ) were obtained from Merck company (Germany), and used without further purifications. Thionly chloride $\left(\mathrm{SOCl}_{2}\right)$ and nitric acid $\left(\mathrm{HNO}_{3}\right)$ were purchased from BDH Chemicals Ltd. The CNTs were supplied from Cheap Tubes Inc. (Grafton, USA).

Grafting of CNTs on FA (CNTs-g-FA). Reported literature based procedure ${ }^{22,23}$, was used to acid functionalize CNTs. Required amount of CNTs $(5 \mathrm{~g})$ were added to $350 \mathrm{~mL}$ of $\mathrm{HNO}_{3}(60 \% \mathrm{v} / \mathrm{v})$ solution in a round bottom flask and then stirred at room temperature for $3 \mathrm{~h}$. The reaction mixture was refluxed at $120^{\circ} \mathrm{C}$ for $12 \mathrm{~h}$, and then cool to room temperature. It was filtrated via vacuum filtration, and the filtrate was washed with de-ionized water until a neutral $\mathrm{pH}$ was obtained. These functionalized CNTs (CNTs-COOH) were dried in vacuum oven at $60{ }^{\circ} \mathrm{C}$ until constant weight. In the second step of synthesis, CNTs-COOH (4 g) were mixed slowly with $60 \mathrm{~mL} \mathrm{SOCl}$ in a $250 \mathrm{~mL}$ round bottom flask at room temperature. After that, the reaction mixture was refluxed at $80^{\circ} \mathrm{C}$ for $24 \mathrm{~h}$. Finally, extra $\mathrm{SOCl}_{2}$ was distilled off and the product was washed with de-ionized water to achieve acyl chloride-functionalized CNTs (CNTs-COCl).

In the final step, a specific amount of selected FA was melted and combined with the CNT-COCl at a ratio of $2: 2(\mathrm{w} / \mathrm{w})$ into a round bottom flask. The mixture was refluxed at $75^{\circ} \mathrm{C}$ for $48 \mathrm{~h}$ with stirring at $100 \mathrm{rpm}$. To 


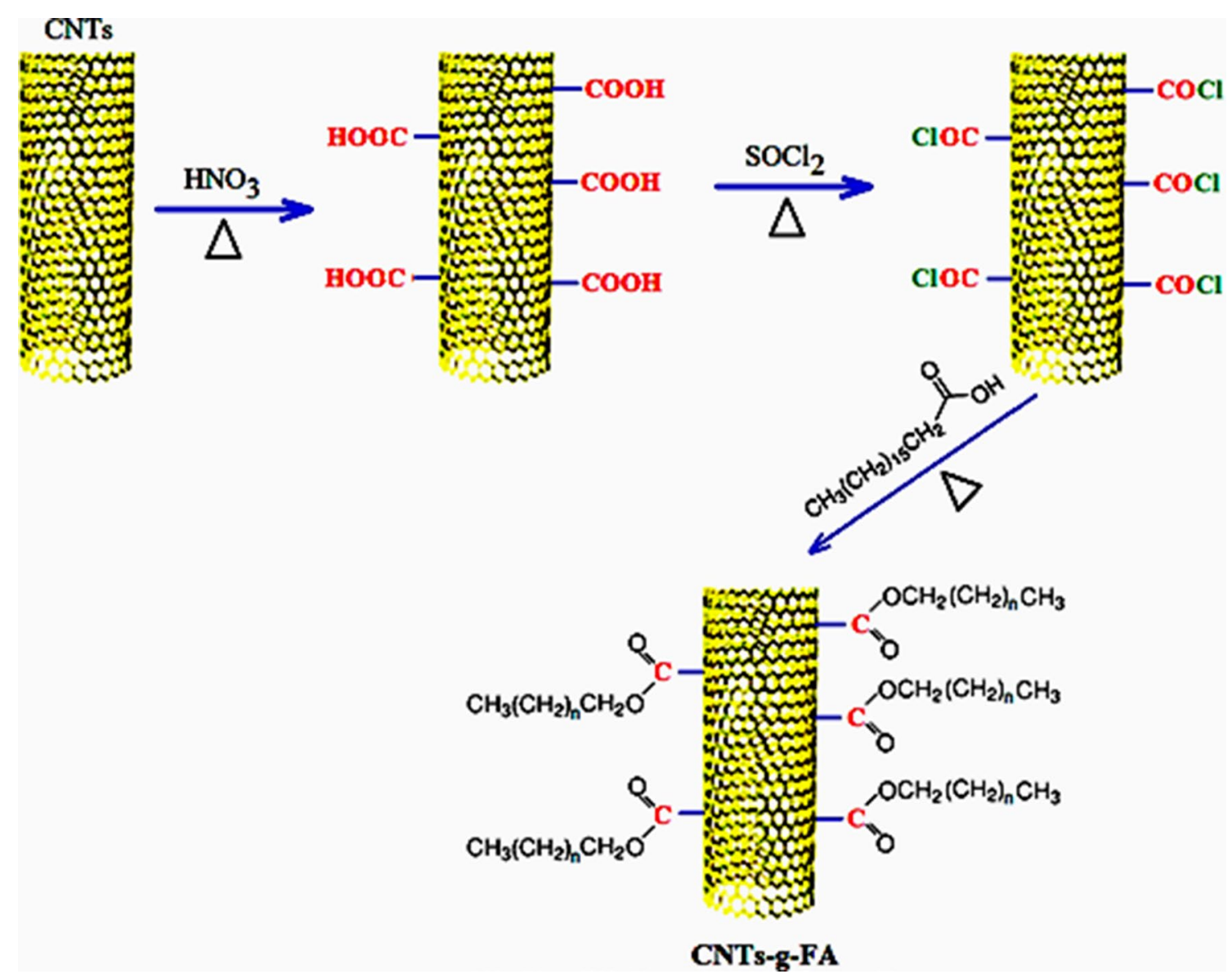

Figure 1. Synthesis/preparation schema for CNTs- $g$-FA.

remove the unreacted FA, the product (CNTs- $g$-FA) was washed carefully, and finally dried in vacuum oven for $24 \mathrm{~h}$. The above-mentioned procedure was repeated to synthesis CNTs- $g$-FA samples for the other weight ratios of CNTs:FA as 3:1, and 1:3 (w/w). The reaction scheme used for the synthesis of CNTs-COOH, CNTs-COCl and CNTs- $g$-FA products is indicated in Fig. 1.

Preparation of FA/CNTs-g-FA and FA/CNTs composites. To prepare FA/CNTs-g-FA composite samples, required amount of FA was melted and slowly mixed with CNTs- $g$-FA (grafting ratio of 2:2) in weight fraction of $95 / 5$ (\%) using a controlled shaker at $200 \mathrm{rpm}$ for $30 \mathrm{~min}$. After thorough mixing, the composite sample was cool to room temperature and stored in a glass bottle for further use. The same method was used to fabricate the other composites using CNTs- $g$-FA with grafting ratio of 3:1 and 1:3 (w/w). For comparison, composite samples with pure CNTs (FA/CNTs) were prepared using the same procedure, as described above. According to grafting ratio, 3:1, 2:2 and 1:3(w/w), the synthesized grafted products were called as CNTs- $g$-FA(3-1), CNTs$g$-FA(2-2) and CNTs- $g$-FA(1-3), whereas the fabricated composite PCMs were named as FA/CNTs- $g$-FA1, FA/ CNTs- $g$-FA2 and FA/CNTs $-g$-FA3, respectively. Moreover, the names of the composite samples doped with nongrafted CNTs were shortened as FA/CNTs. The selected FAs were doped with the same amount (5 wt\%) of CNTs$g$-FA and CNTs additives, separately.

Dispersion stability experiment. To observe the dispersion behavior of the grafted and non-grafted CNTs in FA, the melting/blending method was conducted. As a representative example, the dispersion of CNTs$g$-PA and CNTs in PA was carried out separately. The PA sample at specific amount was melted in two glass tubes at $70{ }^{\circ} \mathrm{C}$. The CNTs- $g$-PA and CNTs powders were added in weight fractions of $5 \mathrm{wt} \%$ to the liquid PA samples. The obtained suspensions were centrifuged at $100 \mathrm{rpm}$ for $20 \mathrm{~min}$ to achieve uniform dispersion. Afterwards, PA/CNTs- $g$-PA and PA/CNTs samples were kept at $70^{\circ} \mathrm{C}$ for $30 \mathrm{~min}$, and studied the dispersion stability.

Characterization methods. The chemical and crystalline structures of the synthesized CNTs-g-FA, FA/ CNTs- $g$-FA and FA/CNTs samples were studied by Fourier-transform infrared (FTIR; Perkin Elmer, 16F PC) and X-ray powder diffraction (XRD) instrument (PANalytical X'-Pert3 model). The FTIR spectra were obtained in wavelength range of 4,000-400 $\mathrm{cm}^{-1}$. The crystalline structures of the samples were identified using $\mathrm{Cu}$ $(\mathrm{K} \alpha=1.5406 \AA)$ irradiation at a step size of $0.0131^{\circ}$. The morphological structures of CNTs- $g$-FA, FA/CNTs$g$-FA, and FA/CNTs samples were investigated using a scanning electron microscope (SEM; LEO 440 model). 
The TES properties of the synthesized CNTs- $g$-FA, FA/CNTs- $g$-FA and FA/CNTs samples were measured by differential scanning calorimetry (DSC; Hitachi-7020) at a heating/cooling rate of $3{ }^{\circ} \mathrm{C} \mathrm{min}{ }^{-1}$. The analyses were repeated for three times to minimize the data error. The average deviation in phase change temperature and latent heat capacity (LHC) measurements was determined as $\pm 0.11{ }^{\circ} \mathrm{C}$ and $\pm 1.15 \%$, respectively. Thermal degradation temperatures of the prepared CNTs- $g$-FA, FA/CNTs- $g$-FA and FA/CNTs samples were determined by thermogravimetric analysis (TGA) technique (Perkin-Elmer). The analysis was performed at heating ramp of $10{ }^{\circ} \mathrm{C} \mathrm{min}-1$ in temperature range of $25-580^{\circ} \mathrm{C}$. The degradation temperature data were determined with average discrepancy of $\pm 1.08^{\circ} \mathrm{C}$. To study the influence of the thermal cycling process on the chemical stability and phase change properties of the prepared FA/CNTs- $g$-FA and FA/CNTs composites, an accelerated heating-cooling process was adapted to the samples using a thermal cycler (Model: BIOER TC-25/H). This treatment was continued until the cycling number reached to 2000. After cycling procedure, FTIR, and DSC analyses were repeated on the studied samples. Thermal conductivity (TC) of CNTs- $g$-FA, FA/CNTs- $g$-FA and FA/CNTs samples as well as pure CA, PA and SA were measured at $20 \pm 1^{\circ} \mathrm{C}$ using a thermal property analyzer (Decagon KD2 pro Devices, Inc., USA). The measurements were repeated three times and the maximum discrepancy was determined as $\pm 0.02 \mathrm{~W} \mathrm{~m}^{-1} \mathrm{~K}$.

\section{Results and discussion}

Microstructural and dispersion stability study. Surface morphology of the CNTs- $g$-FA, FA/CNTs$g$-FA and FA/CNTs composites were studied by SEM analysis. The obtained SEM microstructures are shown in Fig. 2. It is clear from the images (Fig. 2) that the CNTs- $g$-FA are uniformly distributed within the FA/CNTs- $g$-FA composites structure without agglomeration. Moreover, the nanotube phases are more visible on the surface of FA/CNTs composites. It can be assumed that this uniform distribution of the CNTs (both chemically grafted and pure) within the composites creates effective heat conduction path.

Figure 3 exhibits the photographic image of the dispersion study of the grafted and non-grafted CNTs in melted PA as a representative example of other composites. This photograph was taken for PA/CNTs- $g$-PA (5 wt $\%$ ) and PA/CNTs ( $5 \mathrm{wt} \%$ ) composites samples at $70{ }^{\circ} \mathrm{C}$ after $30 \mathrm{~min}$-standby period. As evidently perceived (Fig. 3), some CNTs precipitation was occurred in PA/CNTs sample while the PA/CNTs-g-SA (5 wt\%) had a stable suspension. This result suggested that the grafted CNTs provide better dispersion stability, as compare to that of non-grafted CNTs. It can be directed to the comparatively stronger colloidal interaction between the CNTs- $g$-FA and FA. The similar observation was reported for acid modified CNTs/erythritol suspension ${ }^{21}$ and CNTs- $g$-polyalcohol/paraffin suspensions ${ }^{22}$.

Chemical and crystalline characterization. The FTIR results of the carboxylic acid functionalized CNTs (CNTs-COOH), acyl chloride functionalized CNTs (CNTs-COCl) and fatty acid functionalized CNTs (CNTs- $g$-FA) are shown in Fig. 4. In the spectrum of CNTs-COOH, the wide peak at $3250-3650 \mathrm{~cm}^{-1}$, signified the vibration band of $-\mathrm{OH}$ groups ${ }^{24}$. The peak at $1690 \mathrm{~cm}^{-1}$ is associated with the stretching band of $\mathrm{C}=\mathrm{O}^{25}$ as the peaks at $958 \mathrm{~cm}^{-1}$ and $829 \mathrm{~cm}^{-1}$ are linked with the bending vibration band of $-\mathrm{OH}$ groups ${ }^{26}$. In the spectrum of $\mathrm{CNTs}-\mathrm{COCl}$, the peak at $1776 \mathrm{~cm}^{-1}$ is associated with the stretching band of $\mathrm{C}=\mathrm{O}$ group. The peaks at $1328 \mathrm{~cm}^{-1}$ and $639 \mathrm{~cm}^{-1}$ are due the $\mathrm{C}-\mathrm{O}$ and $\mathrm{C}-\mathrm{Cl}$ groups of acyl chloride functionalized CNTs, respectively.

On the other hand, in the spectra of CNTs- $g$-FA compounds synthesized at three different grafting ratios, the peaks observed in the range of about $2840-2918 \mathrm{~cm}^{-1}$ are characterized as the stretching band of $-\mathrm{CH}_{2}$ and $-\mathrm{CH}_{3}$ groups. The $\mathrm{C}=\mathrm{O}$ and $\mathrm{C}-\mathrm{O}$ stretching bands were shifted to the range of $1295-1296 \mathrm{~cm}^{-1}$ and $1690-1700 \mathrm{~cm}^{-1}$ after grafting reaction. The intensity of $-\mathrm{OH}$ absorption observed at $3400-3650 \mathrm{~cm}^{-1}$ was considerably reduced due to grafting reaction, although it was seen in spectrum of CNTs- $g$-SA3 and CNTs- $g$-PA3 synthesized at highest grafting mole ratio (FA/CNTs mole ratio: $3: 1$ ). The similar observations were reported for grafted lauric acid with graphene oxide ${ }^{26}$. Moreover, the disappearance of the $\mathrm{C}-\mathrm{Cl}$ absorption band in all spectra of CNTs-g-FA compounds also confirmed that the grafting reaction between FA and CNTs-COCl was successfully carried out. As a whole, all of these results shown in Fig. 4 confirm that the FAs were successfully grafted to the CNTs.

Figure 5 shows the FTIR spectra of the prepared FA/CNTs- $g$-FA and FA/CNTs composites. The peaks between $2943-2920 \mathrm{~cm}^{-1}$ and $2945-2918 \mathrm{~cm}^{-1}$ are associated with the stretching band of methyl and methylene groups of nine different FA/CNTs-g-FA composites and three different FA/CNTs composites, respectively. The peaks around $1687-1704 \mathrm{~cm}^{-1}$ and $1691-1697 \mathrm{~cm}^{-1}$ are related with their $\mathrm{C}=\mathrm{O}$ stretching vibration bands. Moreover, the stretching and bending vibrations belong to $\mathrm{C}-\mathrm{O}$ and $\mathrm{C}-\mathrm{H}$ band are detected in the spectra of the composites. When compared to the spectra of CNTs- $g$-FA, the FTIR spectra of the composites does not show any significant shift of the respective key peak position. This result proved that the presence the good chemical compatibility among FAs and CNTs- $g$-FA or CNTs.

On the other hand, the XRD analysis of the prepared FA/CNTs- $g$-FA and FA/CNTs composites were carried out to examine the influence of added CNTs- $g$-FA and CNTs on the crystal structures of SA, PA and CA. Figure 6 shows the XRD diffraction patterns of CNTs- $g$-CA, CNTs- $g$-PA and CNTs- $g$-SA samples. While, the XRD results of CA/CNTs- $g$-CA, PA/CNTs- $g$-PA, SA/CNTs- $g$-SA and CA/CNTs, PA/CNTs and SA/CNTs composites were presented in Fig. 7. The CA, PA and SA grafted CNTs has typical crystalline peaks in $2 \theta$ range of $19.63^{\circ}-43.67^{\circ}, 7.31^{\circ}-27.68^{\circ}$ and $9.68^{\circ}-43.57^{\circ}$, respectively. The characteristic peaks were detected at $7.58^{\circ}-23.38^{\circ}$ for CA/CNTs- $g$-CA, $7.39^{\circ}-24.0^{\circ}$ for PA/CNTs- $g$-PA, $6.59^{\circ}-24.08^{\circ}$ for SA/CNTs- $g$-SA while they are observed at $7.61^{\circ}-23.42^{\circ}$ for $\mathrm{CA} / \mathrm{CNTs}, 7.37^{\circ}-23.95^{\circ}$ for PA/CNTs and $6.62^{\circ}-23.94^{\circ}$ for SA/CNTs composites. Moreover, it is hard to notice the distinctive crystalline peaks of grafted or non-grafted CNTs because their amounts are quite low in the composites ${ }^{27}$. 



Figure 2. SEM images of CNTs- $g$-FA, FA/CNTs- $g$-FA and FA/CNTs composites. 


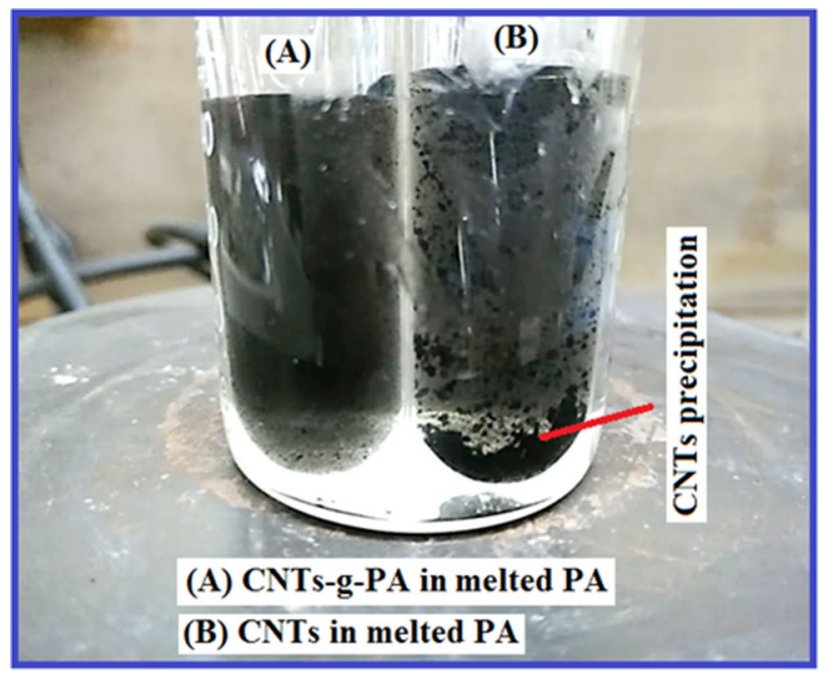

Figure 3. Photograph image of PA/CNTs- $g$-PA ( $5 \mathrm{wt} \%)$ and PA/CNT (5 wt $\%)$ suspensions after $30 \mathrm{~min}$ standby at $70^{\circ} \mathrm{C}$.

LHTES properties. The integration of a PCM with a supporting material causes a significant reduction in the latent heat capacity (LHC) of the composite PCM. However, an adequately high LHC is one of the elementary selection criteria for composite PCMs and phase transition behaviors are crucial parameters to estimate the LHTES properties of composite PCMs. In this regard, the LHTES properties of CNTs- $g$-FA, FA/CNTs- $g$-FA and FA/CNTs composites were analyzed by DSC, and presented in Figs. 8 and 9, and data tabulated in Tables 1 and 2. From these data, it can be clearly observed that the melting and solidification temperatures of the FA were not changed regularly while the melting and freezing LHCs of the composite samples enhanced as expected. The melting temperatures of the CNTs- $g$-FA were changed in the range of $22.44 \pm 0.12-23.35 \pm 0.12{ }^{\circ} \mathrm{C}$ for CNTs$g$-CA, $36.39 \pm 0.11-39.41 \pm 0.11^{\circ} \mathrm{C}$ for CNTs- $g$-PA and $38.62 \pm 0.12-40.43 \pm 0.10{ }^{\circ} \mathrm{C}$ for CNTs- $g$-SA. The phase change temperatures of the composites are very different from those of pure CA $\left(27-32{ }^{\circ} \mathrm{C}\right), \mathrm{PA}\left(62-65^{\circ} \mathrm{C}\right)$ and SA $\left(67-72^{\circ} \mathrm{C}\right)$ due to the change in the heat flow path and mechanism with these new compounds. Depending on the increase in the grafting ratio of FA, the latent heat of fusion of the CNTs- $g$-FA was increased from $24.62 \pm 0.23$ to $83.60 \pm 0.85 \mathrm{~J} \mathrm{~g}^{-1}$ for CNTs- $g$-CA, $24.21 \pm 0.26$ to $87.93 \pm 0.88 \mathrm{~J} \mathrm{~g}^{-1}$ for CNTs- $g$-PA and $27.25 \pm 0.25$ to $93.17 \pm 0.97 \mathrm{~J} \mathrm{~g}^{-1}$ for CNTs- $g$-SA. In addition, the melting temperatures of the composites including $5 \mathrm{wt} \%$ grafted compounds were measured in the range of $28.85 \pm 0.10-29.43 \pm 0.13^{\circ} \mathrm{C}$ for CA/CNTs- $g$-CA, $59.42 \pm 0.10-$ $60.0 \pm 0.10^{\circ} \mathrm{C}$ for PA/CNTs- $g$-PA and $63.82 \pm 0.11-64.90 \pm 0.10^{\circ} \mathrm{C}$ for SA/CNTs- $g$-SA composite. The significant decrease in the melting temperatures of the composite PCMs in comparison with those of pure FAs could be due to the dispersion of CNTs grafted with long-chain FA molecules among the FA crystals. Moreover, the melting temperature was determined as $28.07 \pm 0.10^{\circ} \mathrm{C}$ for CNTs/CA, $59.70 \pm 0.12{ }^{\circ} \mathrm{C}$ for CNTs/PA and $66.5 \pm 0.11^{\circ} \mathrm{C}$ for $\mathrm{CNTs} / \mathrm{SA}$. The phase changes temperatures of the composites including non-grafted CNTs are relatively closer to those of the pure FAs given above. This means that the physical attractions (e.g., capillary and surface tension forces) between the FA and grafted CNTs are more effective compared to the attractions between FA and FA$g$-CNTs. Again, depending on the increase in the grafting ratio of FA, the melting LHCs of the composites were determined, which was in the range of $174-184 \mathrm{~J} \mathrm{~g}^{-1}$ for CA/CNTs- $g$-CA, 214-230 J g ${ }^{-1}$ for PA/CNTs- $g$-PA and 235-257 J g ${ }^{-1}$ for SA/CNTs- $g$-SA. Whereas the melting LHC of CNTs/CA, CNTs/PA and CNTs/SA was found to be about 171, 210 and $234 \mathrm{~J} \mathrm{~g}^{-1}$, respectively. As seen from these data, especially the LHC values of the composites including CNTs-g-FA (grafting ratio: 1:3) were $6.5-8.9 \%$ higher than that of the composites including CNTs due to the LHC contribution of the CNTs-g-FA additive. On the other hand, when compared the LHC of the FA/CNTs- $g$-FA composite PCMs with those of different kinds of organic PCMs doped with carbon based fillers ${ }^{14-20,22,26,29,36}$, it was observed that the FA/CNTs-g-FA composite PCMs prepared in this work had relatively higher LHC than most of them. This boosted in the LHC value of the FA/CNTs-FA composite PCMs was due to the fact that the CNTs- $g$-FA used as doping agents had LHC of in the range of 25-93 J g ${ }^{-1}$.

Cycling phase change reliability and chemical stability of the composite PCMs. The cycling phase change reliability is one of the major characteristic preference of a PCM. Therefore, it is desired that the PCM should have stable phase change behavior after considerable number of heating-cooling cycles ${ }^{24,28}$. Based on this criterion, a cycling test including consecutive cycling process repeated for 2000 times was conducted with the FA/CNTs- $g$-FA ( $5 \mathrm{wt} \%$ ) and CNTs/FA (5 wt\%) composites. Figure 10 shows the DSC results of the samples after the 2,000 cycles, and all LHTES data are summarized in Table 3. By considering the phase change temperature data, it was realized that there was a slight reduction in phase change temperature. The changing quantity was calculated between $-1.22{ }^{\circ} \mathrm{C}$ and $0.40{ }^{\circ} \mathrm{C}$ for melting temperature and between $-1.20{ }^{\circ} \mathrm{C}$ and $0.93{ }^{\circ} \mathrm{C}$ for solidification temperature of FA/CNTs- $g$-FA composites. As for the CNTs/FA composites it was determined in the range of $(-0.11)$ to $(-0.70){ }^{\circ} \mathrm{C}$ and $(-0.90)$ to $(+0.93){ }^{\circ} \mathrm{C}$ for melting and solidification period. On the 



Figure 4. FTIR spectral results of CNTs- $g$-FA. 

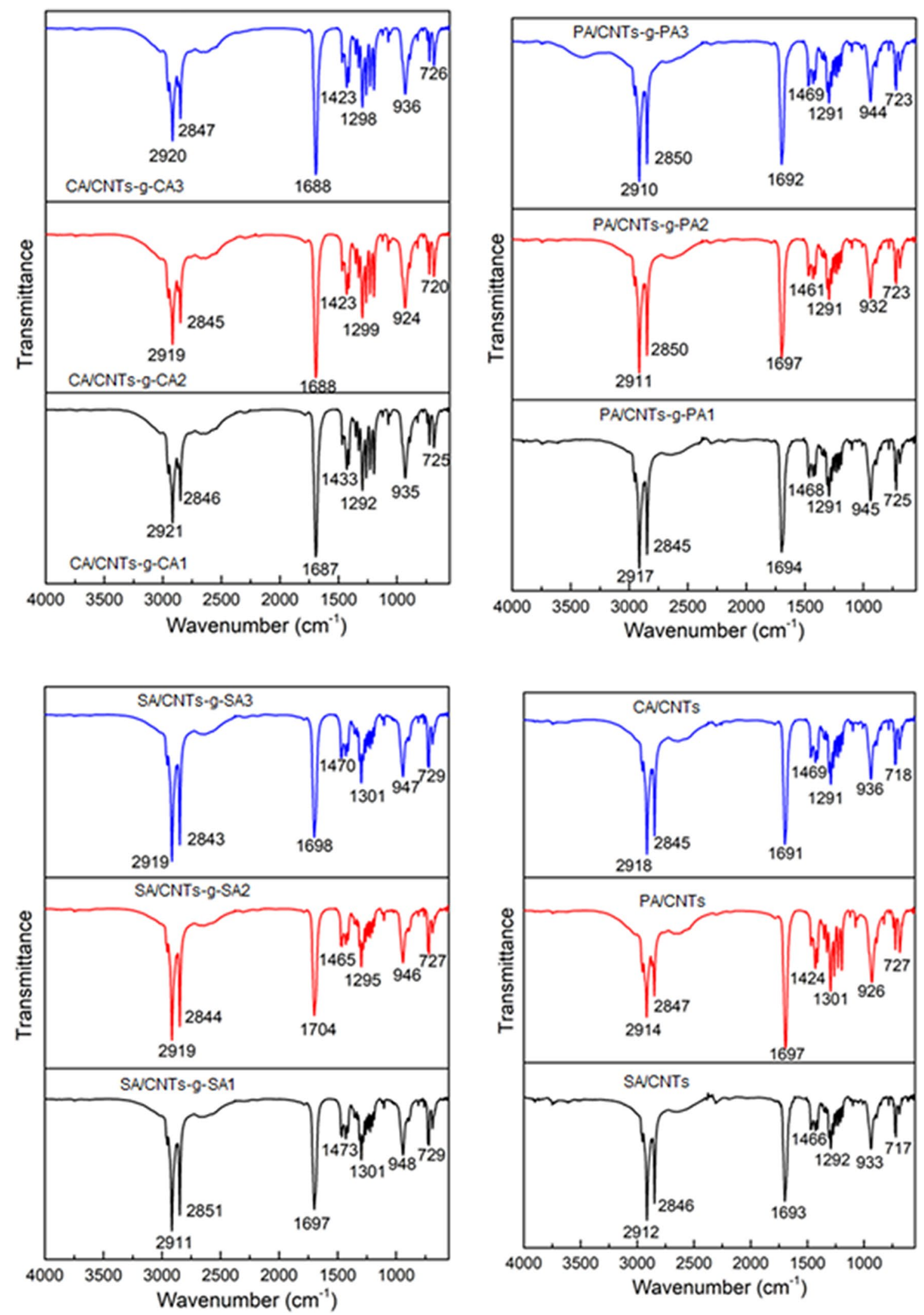

Figure 5. FTIR spectral results of FA/CNTs- $g$-FA and FA/CNTs composites. 

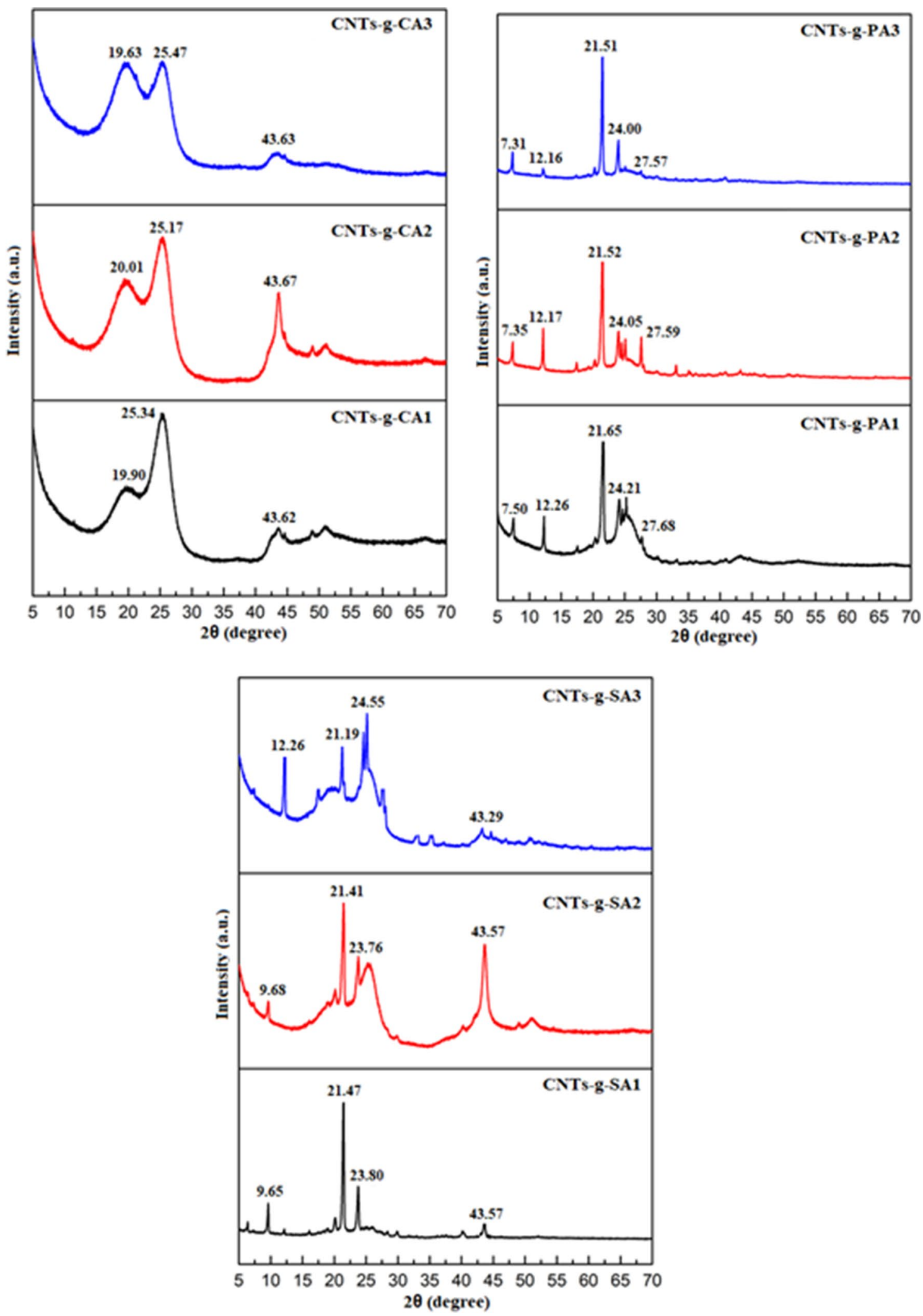

Figure 6. XRD results of CNTs- $g$-FA. 

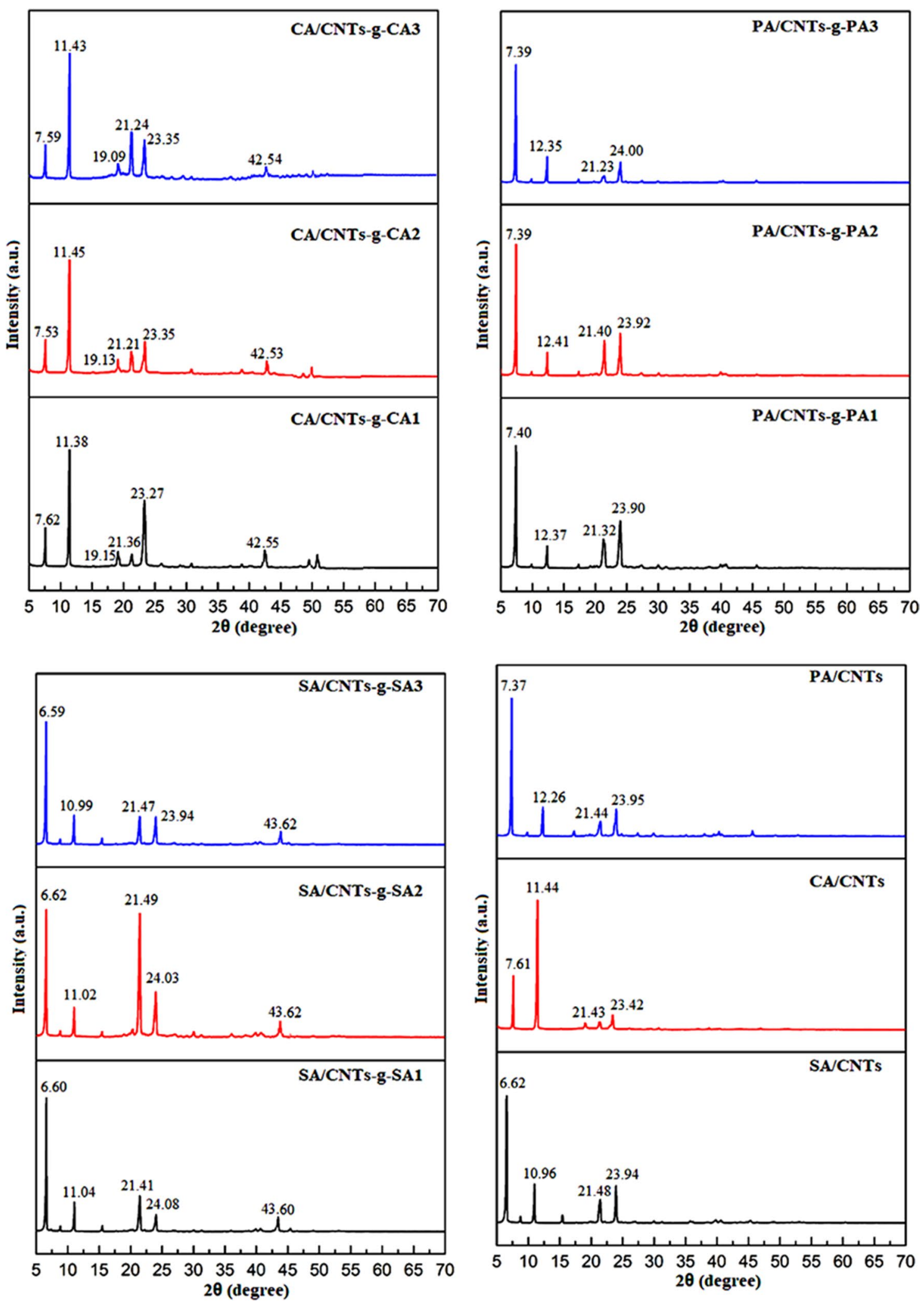

Figure 7. XRD results of FA/CNTs- $g$-FA and FA/CNTs composites.

other hand, the reduction quantity in the LHC values of all FA/CNTs- $g$-FA and CNTs/FA were observed to be in the same level. The decrease in LHC of FA/CNTs- $g$-FA samples was changed from 10.1 to $14.2 \%$ for melting period and from 6.5 to $13.6 \%$ for freezing period. Whereas, it was varied in the range of $9.1-12.5 \%$ for melting 

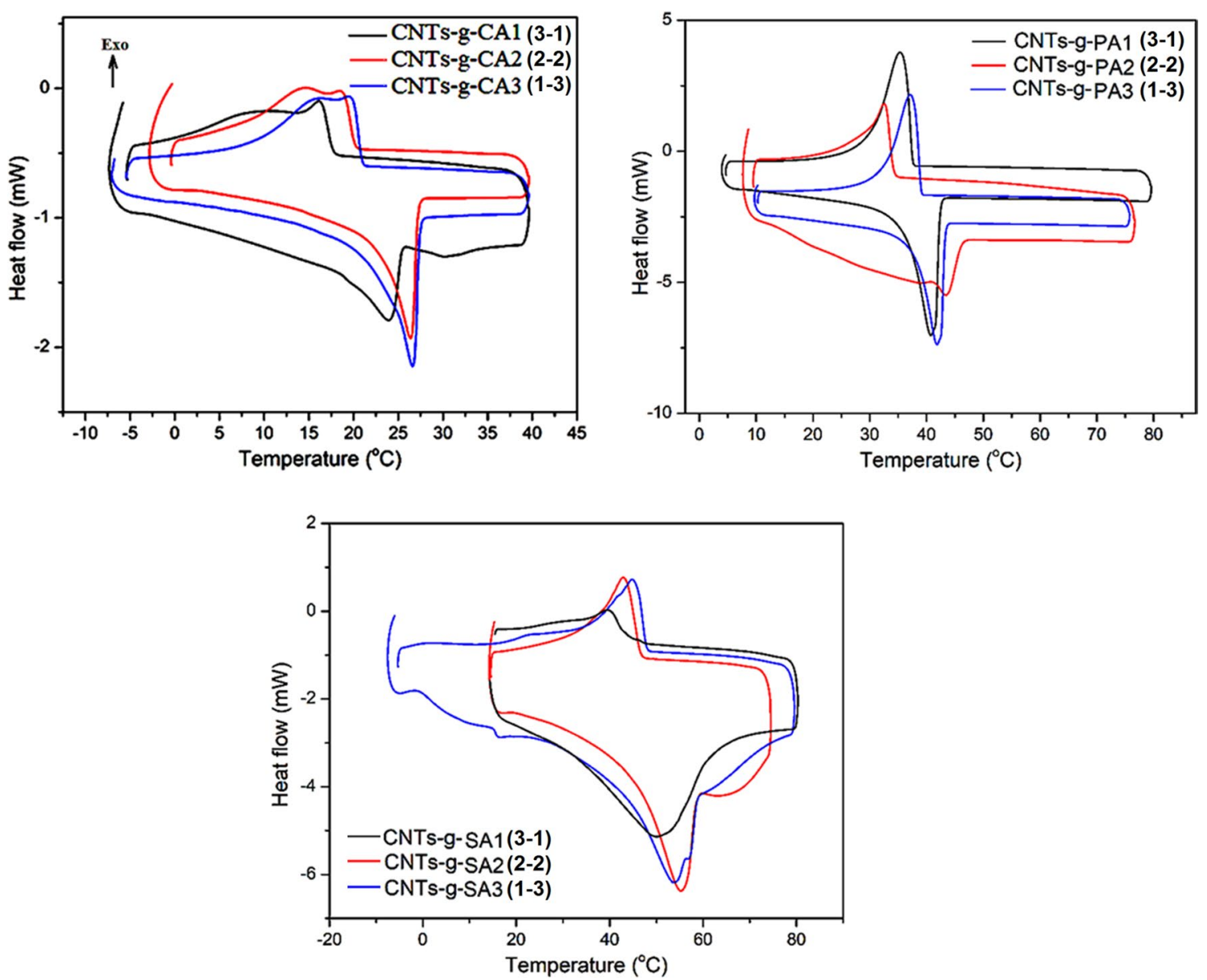

Figure 8. DSC thermograms of CNTs- $g$-FA.

period and 7.7-13.6\% for freezing period of the CNTs/FA composite. By overall evaluation of these results, it can be concluded that the fluctuations in the TES values of all composites were in tolerable range and they had appreciable phase change stability even after 2,000 cycles. Figure 11 compares the FTIR spectra of FA/CNTs$g$-FA (5 wt $\%$ ) and CNTs/FA (5 wt\%) composites before and after the 2,000 cycles. There was no significant shift of peaks were observed in the wavenumber characteristic absorption peaks of all the composites. Additionally, no extra band was observed after the cycling study. This indicates that all the prepared composite PCMs had adequate chemical stability.

Thermal degradation stability of the composite PCMs. Thermal degradation stability is one of the major thermal characteristics considered for any PCM for its suitability in a TES system. With this sense, the thermal degradation stability of the prepared composites was studied and the TGA curves were presented in Fig. 12 and Table 4. As clearly observed from the thermal curves, the prepared CNTs- $g$-FA, FA/CNTs- $g$-FA and FA/CNTs composites showed one-step thermal degradation behavior. Moreover, the grafting ratio of FA was affected thermal degradation temperature range of the final product, CNTs- $g$-FA. The degradation temperature range was determined as, $102 \pm 1.06{ }^{\circ} \mathrm{C}-235 \pm 1.12{ }^{\circ} \mathrm{C} ; 154 \pm 1.11{ }^{\circ} \mathrm{C}-278 \pm 1.23{ }^{\circ} \mathrm{C} ; 180 \pm 1.09{ }^{\circ} \mathrm{C}-280 \pm 1.06{ }^{\circ} \mathrm{C}$ for CA/CNTs- $g$-CA, PA/CNTs- $g$-PA and SA/CNTs- $g$-SA, while it was measured as $108 \pm 1.26^{\circ} \mathrm{C}-200 \pm 1.02^{\circ} \mathrm{C}$; $162 \pm 1.03{ }^{\circ} \mathrm{C}-293 \pm 1.18{ }^{\circ} \mathrm{C} ; 208 \pm 1.22{ }^{\circ} \mathrm{C}-309 \pm 1.21{ }^{\circ} \mathrm{C}$ for CA/CNTs, PA/CNTs and SA/CNTs, respectively. These data indicated that the thermal decomposition temperatures of the FA/CNTs samples were extended slightly. It could be due to the covalent functionalization of CNTs with FA and more effective chemical interface of FA with CNTs- $g$-FA ${ }^{22}$. Consequently, the prepared composite PCMs had adequately thermal degradation stability because the decomposition temperature of each composite PCM is much higher than its own phase change temperature value.

TC of the prepared PCMs. Thermal conductivity (TC) is one of the essential properties for a PCM. The higher the thermal conductivity of the PCM, the faster will be the rate of heat loading or releasing from the TES system. Based on this impression, this study is also focused on the TC enhancement of the FAs by adding CNTs$g$-FA rather than only CNTs. Table 5 presents the measured TC values of CNTs- $g$-FA, FA/CNTs- $g$-FA and FA/ CNTs as well as pure FAs. As noticed from the tabulated data (Table 5), the TC value of the pure FAs are $0.16 \pm 0.01$, $0.17 \pm 0.01$ and $0.19 \pm 0.01 \mathrm{~W} \mathrm{~m}^{-1} \mathrm{~K}^{-1}$ respectively for the CA, PA and SA. It was boosted from $0.49 \pm 0.02$ to 

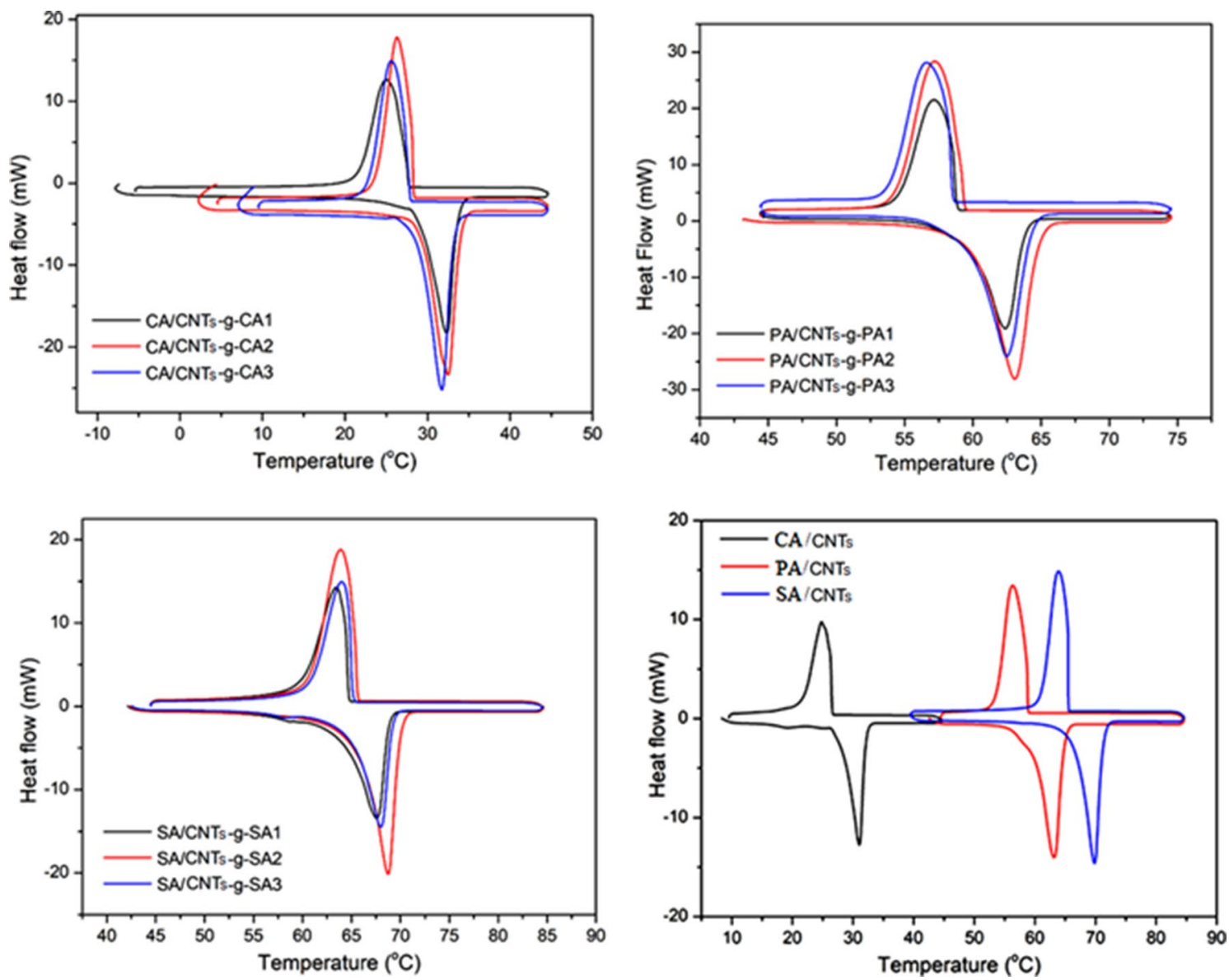

Figure 9. DSC thermograms of FA/CNTs- $g$-FA and FA/CNTs composites.

\begin{tabular}{|l|l|l|l|l|}
\hline Material & Melting temperature $\left({ }^{\circ} \mathbf{C}\right)$ & $\begin{array}{l}\text { Solidification temperature } \\
\left({ }^{\circ} \mathbf{C}\right)\end{array}$ & Melting enthalpy $\left(\mathbf{J ~ g}^{-1}\right)$ & $\begin{array}{l}\text { Solidification enthalpy } \\
\left(\mathbf{J ~ g}^{-1}\right)\end{array}$ \\
\hline CNTs- $g$-CA1 & $22.44 \pm 0.12$ & $18.03 \pm 0.10$ & $24.62 \pm 0.23$ & $-20.57 \pm 0.22$ \\
\hline CNTs- $g$-CA2 & $23.35 \pm 0.11$ & $20.55 \pm 0.12$ & $58.34 \pm 0.57$ & $-52.74 \pm 0.53$ \\
\hline CNTs- $g$-CA3 & $22.00 \pm 0.10$ & $21.10 \pm 0.11$ & $83.60 \pm 0.85$ & $-75.69 \pm 0.78$ \\
\hline CNTs- $g$-PA1 & $36.39 \pm 0.11$ & $36.69 \pm 0.13$ & $24.21 \pm 0.26$ & $-23.85 \pm 0.21$ \\
\hline CNTs- -PA2 & $39.41 \pm 0.11$ & $33.99 \pm 0.10$ & $60.24 \pm 0.62$ & $-54.66 \pm 0.56$ \\
\hline CNTs- $g$-PA3 & $37.28 \pm 0.12$ & $38.99 \pm 0.10$ & $87.93 \pm 0.88$ & $-83.95 \pm 0.81$ \\
\hline CNTs- $g$-SA1 & $38.62 \pm 0.12$ & $43.93 \pm 0.10$ & $27.25 \pm 0.25$ & $-26.22 \pm 0.27$ \\
\hline CNTs- -SA2 & $40.43 \pm 0.10$ & $45.47 \pm 0.11$ & $63.14 \pm 0.61$ & $-57.40 \pm 0.58$ \\
\hline CNTs- $g$-SA3 & $40.41 \pm 0.10$ & $48.26 \pm 0.12$ & $93.17 \pm 0.91$ & $-92.13 \pm 0.91$ \\
\hline
\end{tabular}

Table 1. The LHTES properties of synthesized CNTs- $g$-FA.

$0.82 \pm 0.02 \mathrm{~W} \mathrm{~m}^{-1} \mathrm{~K}^{-1}$ for CNTs- $g$-CA, from $0.51 \pm 0.02$ to $0.89 \pm 0.02 \mathrm{~W} \mathrm{~m}^{-1} \mathrm{~K}^{-1}$ for CNTs- $g$-PA, from $0.54 \pm 0.02$ to $0.93 \pm 0.02 \mathrm{~W} \mathrm{~m}^{-1} \mathrm{~K}^{-1}$ for CNTs- $g$-SA, which depends on the increasing grafting ratio of CNTs. This increase is directly related with the higher amount of CNTs bonding of FAs. Moreover, the TC value was determined in the range of $0.24 \pm 0.01-0.29 \pm 0.01 \mathrm{~W} \mathrm{~m}^{-1} \mathrm{~K}^{-1}$ for CA/CNTs- $g$-CA ( $5 \mathrm{wt} \%$ ) set of composite PCMs, $0.26 \pm 0.01-$ $0.32 \pm 0.01 \mathrm{~W} \mathrm{~m}^{-1} \mathrm{~K}^{-1}$ for PA/CNTs- $g$-PA $\left(5 \mathrm{wt} \%\right.$ ) set of composite PCMs, $0.28 \pm 0.01-0.36 \pm 0.01 \mathrm{~W} \mathrm{~m}^{-1} \mathrm{~K}^{-1}$ for SA/CNTs- $g$-SA ( $5 \mathrm{wt} \%$ ) set of composite PCMs. Compared to the pure FAs, these composites showed linear increase of TC values, it was in the range of 50.0-81.3\% for CA/CNTs- $g$-CA, $52.9-88.22 \%$ for PA/CNTs- $g$-PA and 47.4-89.5\% for SA/CNTs- $g$-SA group of composite PCMs. On the other hand, the improvement (\%) of TC values of CA/CNTs (5 wt\%), PA/CNTs (5 wt\%) and SA/CNTs (5 wt\%) composite PCMs was calculated as 37.5, 70.6 and $68.4 \%$ compared to that of pure CA, PA and SA, respectively. In comparison to pure FAs or FA/CNTs composites, a higher degree of TC enhancement was observed from the FA/CNTs- $g$-FA composite PCMs, which was attributed to their increased interfacial compatibility/or interfacial contact area between the grafted CNTs and $\mathrm{FA}^{23,29}$. Relatively better miscibility and affinity between the covalent functionalized CNTs and FAs allowed improving interfacial thermal transport and thus remarkably enriching their TC values ${ }^{22,26,30,31}$. Accordingly, 


\begin{tabular}{|l|l|l|l|l|}
\hline Material & Melting temperature $\left({ }^{\circ} \mathbf{C}\right)$ & $\begin{array}{l}\text { Solidification temperature } \\
\left({ }^{\circ} \mathbf{C}\right)\end{array}$ & Melting enthalpy $\left(\mathbf{J ~ g}^{-1}\right)$ & $\begin{array}{l}\text { Solidification enthalpy } \\
\left(\mathbf{~ g ~}^{-1}\right)\end{array}$ \\
\hline CA/CNTs- $g$-CA1 & $28.85 \pm 0.10$ & $28.07 \pm 0.11$ & $174.12 \pm 1.73$ & $-173.65 \pm 1.76$ \\
\hline CA/CNTs-g-CA2 & $29.43 \pm 0.13$ & $28.57 \pm 0.13$ & $179.03 \pm 1.81$ & $-178.76 \pm 1.83$ \\
\hline CA/CNTs- $g$-CA3 & $28.84 \pm 0.12$ & $27.95 \pm 0.10$ & $183.45 \pm 1.85$ & $-180.46 \pm 1.83$ \\
\hline PA/CNTs- $g$-PA1 & $59.42 \pm 0.10$ & $58.97 \pm 0.10$ & $214.23 \pm 2.03$ & $-213.38 \pm 2.17$ \\
\hline PA/CNTs- $g$-PA2 & $60.00 \pm 0.10$ & $59.57 \pm 0.11$ & $224.26 \pm 1.98$ & $-222.78 \pm 2.34$ \\
\hline PA/CNTs- $g$-PA3 & $59.61 \pm 0.11$ & $58.45 \pm 0.10$ & $230.18 \pm 2.01$ & $-228.96 \pm 2.34$ \\
\hline SA/CNTs- $g$-SA1 & $63.82 \pm 0.11$ & $65.08 \pm 0.11$ & $235.37 \pm 2.23$ & $-233.21 \pm 2.09$ \\
\hline SA/CNTs- $g$-SA2 & $64.73 \pm 0.12$ & $65.92 \pm 0.12$ & $243.25 \pm 2.52$ & $-242.43 \pm 2.47$ \\
\hline SA/CNTs- $g$-SA3 & $64.90 \pm 0.10$ & $65.12 \pm 0.11$ & $256.67 \pm 2.63$ & $-255.56 \pm 2.61$ \\
\hline CNTs/CA & $28.07 \pm 0.10$ & $26.54 \pm 0.13$ & $171.43 \pm 1.73$ & $-171.34 \pm 1.73$ \\
\hline CNTs/PA & $59.70 \pm 0.12$ & $59.10 \pm 0.10$ & $210.67 \pm 2.13$ & $-209.53 \pm 2.13$ \\
\hline CNTs/SA & $66.50 \pm 0.11$ & $66.90 \pm 0.10$ & $233.86 \pm 2.23$ & $-233.38 \pm 2.43$ \\
\hline
\end{tabular}

Table 2. The LHTES properties of FA/CNTs- $g$-FA and FA/CNTs composites.
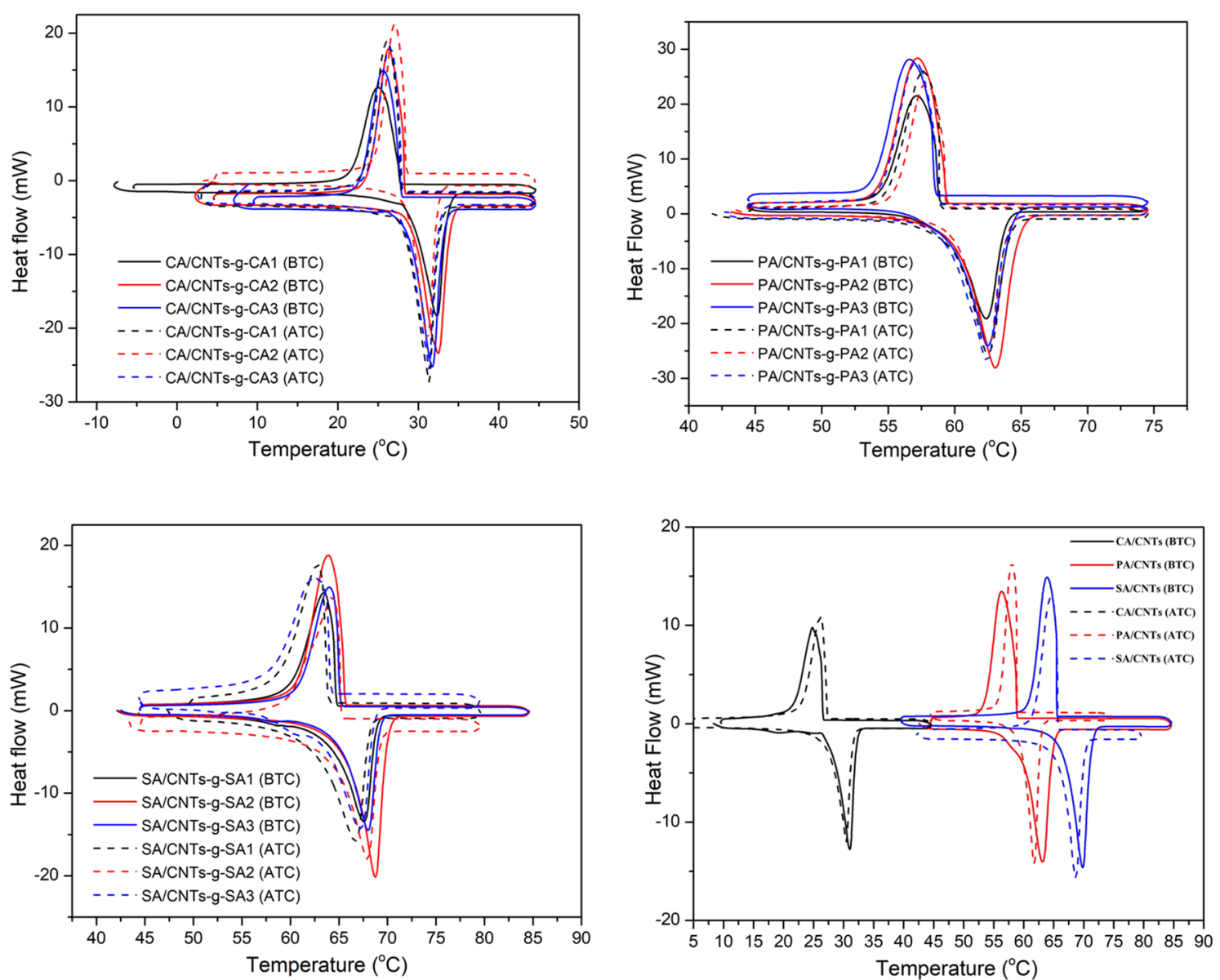

Figure 10. DSC thermograms of FA/CNTs- $g$-FA and FA/CNTs composites before and after 2000 cycles. 


\begin{tabular}{|c|c|c|c|c|c|c|c|c|}
\hline Material & $\begin{array}{l}\text { Melting temperature } \\
\left({ }^{\circ} \mathrm{C}\right)\end{array}$ & Change $\left({ }^{\circ} \mathrm{C}\right)$ & \begin{tabular}{|l} 
Solidification \\
temperature $\left({ }^{\circ} \mathrm{C}\right)$
\end{tabular} & Change $\left({ }^{\circ} \mathrm{C}\right)$ & $\begin{array}{l}\text { Melting enthalpy } \\
\left(\mathrm{J} \mathrm{g}^{-1}\right)\end{array}$ & Reduction (\%) & $\begin{array}{l}\text { Solidification } \\
\text { enthalpy }\left(\mathrm{J} \mathrm{g}^{-1}\right)\end{array}$ & Reduction (\%) \\
\hline CA/CNTs- $g$-CA1 & $28.27 \pm 0.13$ & -0.58 & $27.64 \pm 0.12$ & -0.43 & $151.21 \pm 1.53$ & 13.2 & $-151.12 \pm 1.53$ & 12.9 \\
\hline CA/CNTs- $g$-CA2 & $28.60 \pm 0.10$ & -0.83 & $28.80 \pm 0.12$ & 0.23 & $154.13 \pm 1.57$ & 13.9 & $-155.34 \pm 1.56$ & 13.1 \\
\hline CA/CNTs- $g$-CA3 & $28.40 \pm 0.10$ & -0.44 & $28.16 \pm 0.10$ & 0.21 & $157.45 \pm 1.53$ & 14.2 & $-158.56 \pm 1.66$ & 12.1 \\
\hline PA/CNTs-g-PA1 & $59.82 \pm 0.11$ & 0.40 & $58.99 \pm 0.11$ & 0.02 & $192.67 \pm 1.94$ & 10.1 & $-199.50 \pm 2.13$ & 6.5 \\
\hline PA/CNTs- $g$-PA2 & $60.01 \pm 0.11$ & 0.01 & $59.43 \pm 0.10$ & -0.14 & $193.54 \pm 1.96$ & 13.7 & $-192.33 \pm 1.97$ & 13.6 \\
\hline PA/CNTs- $g$-PA3 & $59.39 \pm 0.11$ & -0.22 & $58.81 \pm 0.13$ & 0.36 & $201.34 \pm 1.99$ & 12.5 & $-199.54 \pm 2.13$ & 12.8 \\
\hline SA/CNTs- $g$-SA1 & $62.60 \pm 0.10$ & -1.22 & $63.88 \pm 0.11$ & -1.20 & $204.34 \pm 2.03$ & 13.2 & $-203.32 \pm 2.08$ & 12.8 \\
\hline SA/CNTs- $g$-SA2 & $64.61 \pm 0.12$ & -0.12 & $65.21 \pm 0.10$ & -0.71 & $217.27 \pm 2.18$ & 10.7 & $-215.04 \pm 2.23$ & 11.3 \\
\hline SA/CNTs-g-SA3 & $64.60 \pm 0.11$ & -0.30 & $64.20 \pm 0.11$ & -0.92 & $221.19 \pm 2.31$ & 13.8 & $-219.67 \pm 2.23$ & 11.4 \\
\hline CNTs/CA & $27.40 \pm 0.12$ & -0.67 & $27.47 \pm 0.10$ & 0.93 & $151.33 \pm 1.53$ & 11.7 & $-153.01 \pm 1.57$ & 10.6 \\
\hline $\mathrm{CNTs} / \mathrm{PA}$ & $59.59 \pm 0.10$ & -0.11 & $58.88 \pm 0.12$ & -0.22 & $191.45 \pm 1.87$ & 9.1 & $-193.32 \pm 1.98$ & 7.7 \\
\hline CNTs/SA & $65.80 \pm 0.11$ & -0.70 & $66.00 \pm 0.10$ & -0.90 & $204.67 \pm 2.03$ & 12.5 & $-201.54 \pm 2.18$ & 13.6 \\
\hline
\end{tabular}

Table 3. The LHTES properties of FA/CNTs- $g$-FA and FA/CNTs composites after 2000 thermal cycles.

CNTs- $g$-FA acted as good filler to increase TC of the FAs by reducing interfacial thermal resistance ${ }^{32,33}$. Similar phenomenon was observed for the erythritol as PCM by adding acid-functionalized CNTs ${ }^{21}$. Additionally, the effect of the thermal cycling operation on the TC property of the produced FA/CNTs- $g$-FA and FA/CNTs composites were also investigated. As seen from the tabulated data in Table 5, the TC values was not changed in the most of composite samples, while it was slightly boosted for few samples, mainly due to slight improvement in the dispersion stability after the thermal cycling. On the other hand, the measured TC values of FA/CNTs- $g$-FA and FA/CNTs composites were compared with those of some PCMs doped with different kind of carbon basedfillers in Table 6. As seen from the tabulated data, the CPCM prepared in this work had much superior thermal properties than the previously reported similar PCMs ${ }^{14,20,22,26,34-36}$.

\section{Conclusions}

In the present study, CNTs was functionalized and three FAs (CA, PA and SA) were grafted separately at three different ratios. FTIR, SEM and XRD techniques were used to investigate the grafting reactions, the surface modification of CNTs, compatibility and crystallites of the components. The synthesized materials were then used as additive in a mass fraction of $5 \mathrm{wt} \%$ to prepare respective composites to achieve good LHC and at the same time to boost the TC of the PCMs. The TES properties, thermal degradation temperatures and TC values of all prepared composite PCMs were measured. Moreover, their cycling phase change reliability and chemical structure stability were studied. The chemical structure and crystallites of the CNTs- $g$-FA, FA/CNTs- $g$-FA and FA/CNTs were confirmed by FTIR and XRD, and the surface morphologies of the different composite PCMs were evaluated by SEM. The melting temperatures of the composites containing $5 \mathrm{wt} \%$ non-grafted and FA grafted CNT additives were measured in the range of about $28-67^{\circ} \mathrm{C}$ and $29-65^{\circ} \mathrm{C}$, respectively. While their corresponding LHC values of about $171-234 \mathrm{~J} \mathrm{~g}^{-1}$ and $183-257 \mathrm{~J} \mathrm{~g}^{-1}$, respectively. After 2000 , cycles, the melting temperature of FA/CNTs- $g$-FA composites was changed between $-1.22^{\circ} \mathrm{C}$ and $0.40{ }^{\circ} \mathrm{C}$, as it was determined in the range of $(-0.11)$ to $(-0.70)^{\circ} \mathrm{C}$ and CNTs/FA composites. The cycling results also revealed that all composite PCMs had appreciable phase change stability and good chemical stability even after 2,000 cycles. The composites including grafted CNTs and non-grafted CNTs additives were thermally degraded in temperature interval of around $102-280^{\circ} \mathrm{C}$ and $108-309^{\circ} \mathrm{C}$, respectively. These data proved that the composites had satisfactory thermal stability. Compared to the pure FAs, the TC values of the composite PCMs were increased in the range of about $50-90 \%$ by adding CNTs- $g$-FA in mass fraction of $5 \mathrm{wt} \%$, while the TC values of the composites were boosted in the range of about $38-68 \%$ in case of adding same amount of pure CNTs. The relatively higher improvements in TCs and LHCs of the composites doped with grafted CNTs were due to the better dispersion and affinity compared to non-grafted CNTs. In addition, thermal cycling treatment had an insignificant effect on the TC values of all composite PCMs. Consequently, good dispersion stability, phase change temperatures, LHC properties, enhanced TC values, cycling thermal/chemical stability and high thermal degradation temperatures make the FAs doped with CNTs- $g$-FA additive very suitable large-scale practice TES applications. 

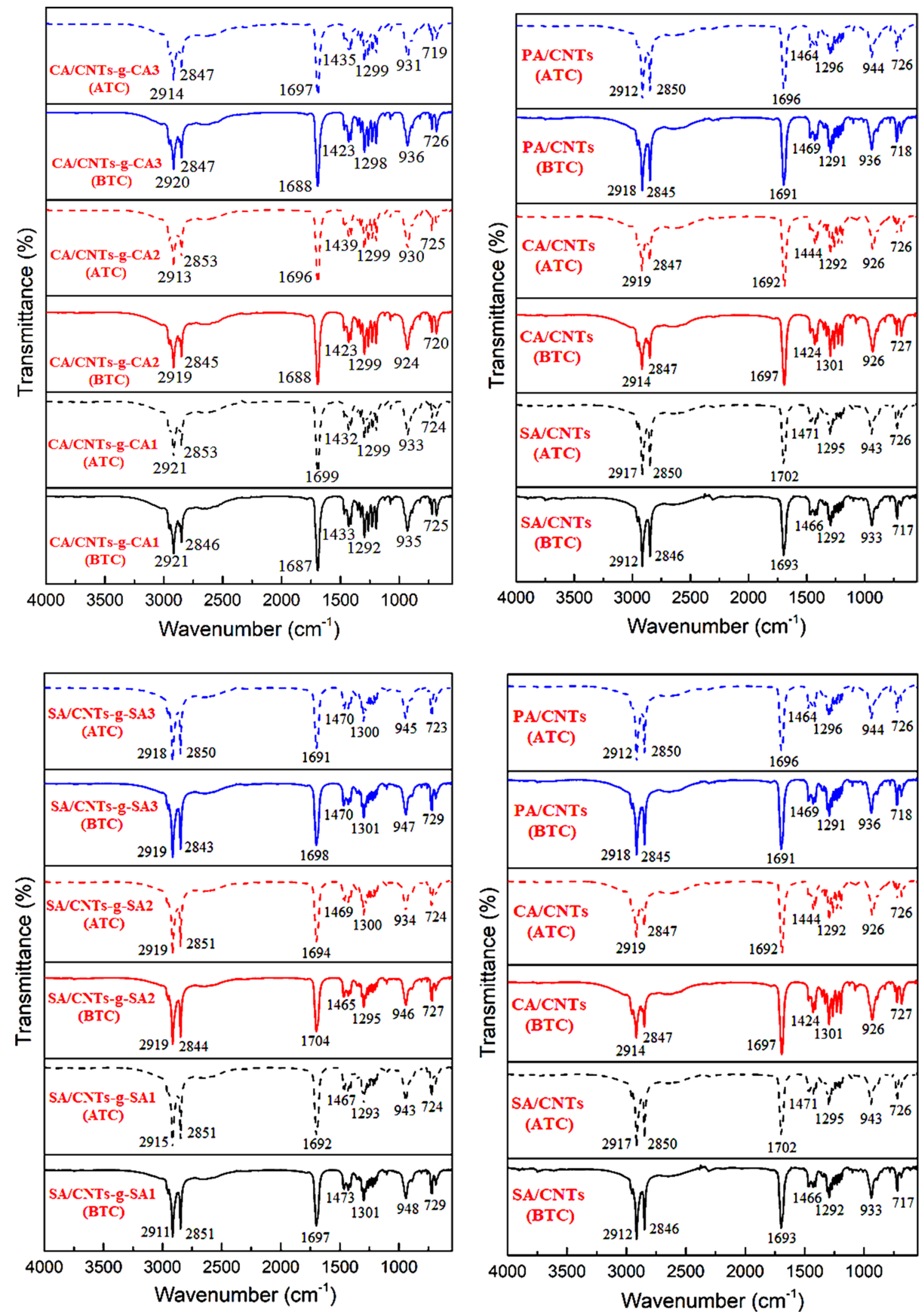

Figure 11. FTIR results of FA/CNTs- $g$-FA and FA/CNTs composites before (BTC) and after (ATC) 2,000 cycles. 

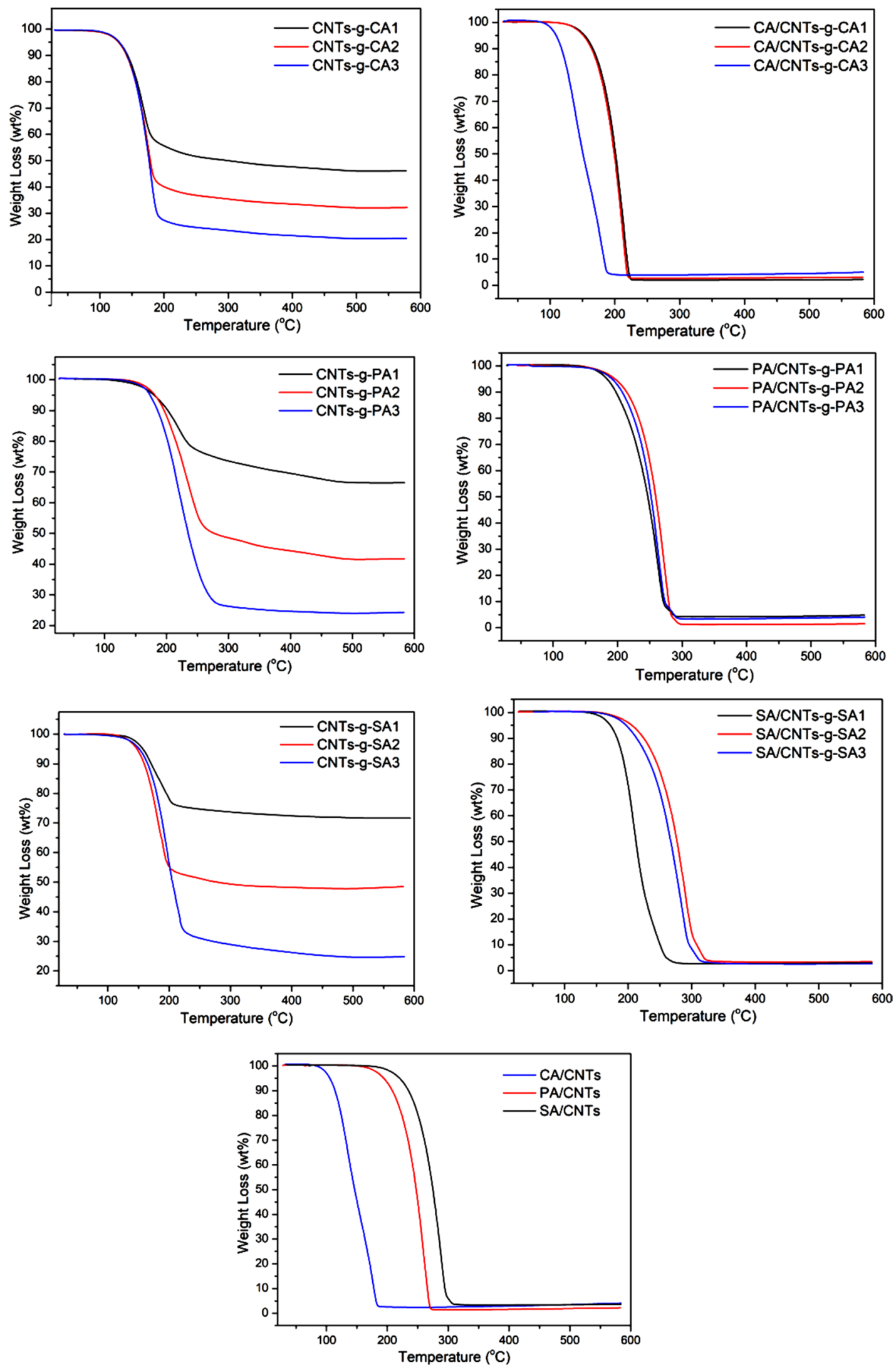

Figure 12. TGA thermograms of the synthesized CNTs- $g$-FA, FA/CNTs- $g$-FA and FA/CNTs. 


\begin{tabular}{|l|l|}
\hline Material & Degradation temperature $\left({ }^{\circ} \mathrm{C}\right)$ \\
\hline CNTs- $g$-CA1 & $122 \pm 1.07-200 \pm 1.03$ \\
\hline CNTs- $g$-CA2 & $122 \pm 1.13-201 \pm 1.09$ \\
\hline CNTs- $g$-CA3 & $122 \pm 1.12-202 \pm 1.10$ \\
\hline CA/CNTs- $g$-CA1 & $142 \pm 1.07-235 \pm 1.02$ \\
\hline CA/CNTs- $g$-CA2 & $142 \pm 1.09-235 \pm 1.10$ \\
\hline CA/CNTs- $g$-CA3 & $112 \pm 1.07-198 \pm 1.06$ \\
\hline CNTs- $g$-PA1 & $154 \pm 1.07-276 \pm 1.05$ \\
\hline CNTs- $g$-PA2 & $154 \pm 1.03-277 \pm 1.09$ \\
\hline CNTs- $g$-PA3 & $154 \pm 1.06-278 \pm 1.11$ \\
\hline PA/CNTs- $g$-PA1 & $158 \pm 1.08-301 \pm 1.10$ \\
\hline PA/CNTs- $g$-PA2 & $158 \pm 1.03-305 \pm 1.13$ \\
\hline PA/CNTs- $g$-PA3 & $158 \pm 1.05-301 \pm 1.11$ \\
\hline CNTs- $g$-SA1 & $148 \pm 1.07-204 \pm 1.12$ \\
\hline CNTs- $g$-SA2 & $148 \pm 1.01-206 \pm 1.06$ \\
\hline CNTs- $g$-SA3 & $148 \pm 1.07-218 \pm 1.12$ \\
\hline SA/CNTs- $g$-SA1 & $160 \pm 1.07-280 \pm 1.06$ \\
\hline SA/CNTs- $g$-SA2 & $180 \pm 1.07-248 \pm 1.10$ \\
\hline SA/CNTs- $g$-SA3 & $180 \pm 1.07-248 \pm 1.03$ \\
\hline CA/CNTs & $108 \pm 1.07-200 \pm 1.08$ \\
\hline PA/CNTs & $162 \pm 1.02-293 \pm 1.09$ \\
\hline SA $/ C N T s$ & $208 \pm 1.05-309 \pm 1.07$ \\
\hline & \\
\hline
\end{tabular}

Table 4. Thermal degradation temperature range of CNTs- $g$-FA, FA/CNTs- $g$-FA and FA/CNTs composites.

\begin{tabular}{|c|c|c|}
\hline Material & TC value $(\mathrm{W} / \mathrm{mK})(\mathrm{BTC})$ & TC value $(\mathrm{W} / \mathrm{mK})$ (ATC) \\
\hline $\mathrm{CA}$ & $0.16 \pm 0.01$ & Not measured \\
\hline $\mathrm{PA}$ & $0.17 \pm 0.02$ & Not measured \\
\hline SA & $0.19 \pm 0.01$ & Not measured \\
\hline CNTs- $g$-CA1 & $0.82 \pm 0.02$ & $0.83 \pm 0.02$ \\
\hline CNTs-g-CA2 & $0.66 \pm 0.02$ & $0.66 \pm 0.02$ \\
\hline $\mathrm{CNTs}-g$-CA3 & $0.49 \pm 0.02$ & $0.49 \pm 0.02$ \\
\hline CA/CNTs-g-CA1 & $0.29 \pm 0.01$ & $0.29 \pm 0.01$ \\
\hline CA/CNTs- $g$-CA2 & $0.27 \pm 0.01$ & $0.28 \pm 0.01$ \\
\hline $\mathrm{CA} / \mathrm{CNTs}-\mathrm{g}$-CA3 & $0.24 \pm 0.01$ & $0.24 \pm 0.01$ \\
\hline CNTs- $g$-PA1 & $0.89 \pm 0.02$ & $0.89 \pm 0.02$ \\
\hline CNTs- $g$-PA2 & $0.68 \pm 0.02$ & $0.69 \pm 0.02$ \\
\hline CNTs- $g$-PA3 & $0.51 \pm 0.02$ & $0.51 \pm 0.02$ \\
\hline PA/CNTs- $g$-PA1 & $0.32 \pm 0.01$ & $0.32 \pm 0.01$ \\
\hline PA/CNTs- $g$-PA2 & $0.28 \pm 0.01$ & $0.29 \pm 0.01$ \\
\hline $\mathrm{PA} / \mathrm{CNTs}-\mathrm{g}$-PA3 & $0.26 \pm 0.01$ & $0.27 \pm 0.01$ \\
\hline CNTs- $g$-SA1 & $0.93 \pm 0.02$ & $0.94 \pm 0.02$ \\
\hline CNTs- $g-\mathrm{SA} 2$ & $0.73 \pm 0.02$ & $0.73 \pm 0.02$ \\
\hline CNTs- $g$-SA3 & $0.54 \pm 0.02$ & $0.55 \pm 0.02$ \\
\hline SA/CNTs- $g$-SAl & $0.36 \pm 0.01$ & $0.36 \pm 0.01$ \\
\hline SA/CNTs- $g$-SA2 & $0.30 \pm 0.01$ & $0.31 \pm 0.01$ \\
\hline SA/CNTs- $g$-SA3 & $0.28 \pm 0.01$ & $0.29 \pm 0.01$ \\
\hline CA/CNTs & $0.22 \pm 0.01$ & $0.22 \pm 0.01$ \\
\hline $\mathrm{PA} / \mathrm{CNTs}$ & $0.29 \pm 0.01$ & $0.30 \pm 0.01$ \\
\hline SA/CNTs & $0.32 \pm 0.01$ & $0.32 \pm 0.01$ \\
\hline
\end{tabular}

Table 5. The measured TC values of FA/CNTs- $g$-FA and FA/CNTs composites before thermal cycling (BTC) and after thermal cycling (ATC). 


\begin{tabular}{|c|c|c|c|c|}
\hline PCM & Carbon based filler & Doping amount (wt\%) & Increase in TC (\%) & References \\
\hline Stearic acid (SA) & CNTs & 2.0 & 61.5 & 14 \\
\hline SA & CNTs & 6.0 & 92.3 & 14 \\
\hline SA & CNTs & 10.0 & 119.2 & 14 \\
\hline $\mathrm{PA}$ & CNTs & 1.0 & 36.44 & 20 \\
\hline $\mathrm{PA}$ & Oxidized CNTs & 1.0 & 39.25 & 20 \\
\hline $\mathrm{PA}$ & Grafted CNTs & 1.0 & 34.11 & 20 \\
\hline Paraffin & Tetradecyl alcohol-g-CNT & 4.0 & 239.13 & 22 \\
\hline Paraffin & Stearyl alcohol-g-CNT & 4.0 & 243.47 & 22 \\
\hline Paraffin & Octanol-g-CNTs & 4.0 & 234.78 & 22 \\
\hline Lauric acid(LA) & LA-g-graphene aerogel & 5.0 & 352.10 & 26 \\
\hline Cetyl alcohol/HDPE & Carbon nanofiber & 5.0 & 256.68 & 34 \\
\hline Stearyl alcohol/HDPE & Expanded graphite & 3.0 & 240.69 & 35 \\
\hline Octadecanol & Graphene & 1.5 & 44.35 & 36 \\
\hline CA & CNTs-g-CA & 5.0 & 81.30 & This work \\
\hline $\mathrm{PA}$ & CNTs-g-PA & 5.0 & 88.22 & This work \\
\hline SA & CNTs-g-SA & 5.0 & 89.50 & This work \\
\hline $\mathrm{CA}$ & CNTs & 5.0 & 37.50 & This work \\
\hline $\mathrm{PA}$ & CNTs & 5.0 & 70.60 & This work \\
\hline SA & CNTs & 5.0 & 68.40 & This work \\
\hline
\end{tabular}

Table 6. Comparison of the TC values of some organic PCMs doped with modified and non-modifed carbon based fillers.

Received: 28 March 2020; Accepted: 20 August 2020

Published online: 21 September 2020

\section{References}

1. Elias, C. N. \& Stathopoulo, V. N. A comprehensive review of recent advances in materials aspects of phase change materials in thermal energy storage. Energy Proc. 161, 385-394 (2019).

2. Veerakumar, C. \& Sreekumar, A. Phase change material based cold thermal energy storage: Materials, techniques and applicationsA review. Int. J. Refrig. 67, 271-289 (2016).

3. Yuan, Y., Zhang, N., Tao, W., Cao, X. \& He, Y. Fatty acids as phase change materials: A review. Renew. Sust. Energy Rev. 29, 482-498 (2014).

4. Rozanna, D. et al. Fatty acids as phase change materials (PCMs) for thermal energy storage: A review. Int. J. Green Energy 1(4), 495-513 (2004).

5. Yuan, Y., Zhang, N., Tao, W., Cao, X. \& He, Y. Fatty acids as phase change materials: A review. Renew. Sustain. Energy Rev. 29, 482-498 (2014).

6. Nomura, T. et al. High thermal conductivity phase change composite with percolating carbon fiber network. Appl. Energy 154, 678-685 (2015).

7. Donga, K. et al. A high-thermal-conductivity, high-durability phase-change composite using a carbon fibre sheet as a supporting matrix. Appl. Energy 264, 114685 (2020).

8. Hashempour, S. \& Vakili, M. H. Preparation and characterisation of nano enhanced phase change material by adding carbon nano tubes to butyl stearate. J. Exp. Nanosci. 13(1), 188-198 (2018).

9. Kumaresan, V., Velraj, R. \& Das, S. K. The effect of carbon nanotubes in enhancing the thermal transport properties of PCM during solidification. Heat Mass Transf. 48, 1345-1355 (2012).

10. Putra, N. et al. Preparation of beeswax/multi-walled carbon nanotubes as novel shapestable nanocomposite phase-change material for thermal energy storage. J. Energy Storage. 21, 32-39 (2019).

11. Farzanehnia, A., Khatibi, M., Sardarabadi, M. \& Passandideh-Fard, M. Experimental investigation of multiwall carbon nanotube/ paraffin based heat sink for electronic device thermal management. Energy Convers. Manag. 179, 314-325315 (2019).

12. Yadav, C. \& Sahoo, R. R. Experimental analysis for optimum thermal performance and thermo-physical parameters of MWCNT based capric acid PCM by using T-history method. Powder Technol. 364, 392-403 (2020).

13. Liu, P. et al. Capric acid hybridizing fly ash and carbon nanotubes as a novel shape-stabilized phase change material for thermal energy storage. ACS Omega 4, 14962-14969 (2019).

14. Yang, L., Zhang, N., Yuan, Y., Cao, X. \& Xiang, B. Thermal performance of stearic acid/carbon nanotube composite phase change materials for energy storage prepared by ball milling. Int. J. Energy Res. 43, 6327-6336 (2019).

15. Li, B. et al. Stearic-acid/carbon-nanotube composites with tailored shape-stabilized phase transitions and light-heat conversion for thermal energy storage. Energy Convers. Manag. 98, 314-321 (2015).

16. Wang, J., Xie, H., Xin, Z. \& Li, Y. Increasing the thermal conductivity of palmitic acid by the addition of carbon nanotubes. Carbon 48, 3979-3986 (2010).

17. Wang, J., Xie, H., Xin, Z., Li, Y. \& Chen, L. Enhancing thermal conductivity of palmitic acid based phase change materials with carbon nanotubes as fillers. Sol. Energy 84, 339-344 (2010).

18. Wang, J., Xie, H. \& Xin, Z. Preparation and thermal properties of grafted CNTs composites. J. Mater. Sci. Technol. 27(3), 233-238 (2011).

19. Ji, P., Sun, H., Zhong, Y. \& Feng, W. Improvement of the thermal conductivity of a phase change material by the functionalized carbon nanotubes. Chem. Eng. Sci. 81, 140-145 (2012).

20. Xiao, D. et al. Study on the phase change thermal storage performance of palmitic acid/carbon nanotubes composites. Compos. Part A 77, 50-55 (2015). 
21. Shen, S. et al. The effects of modified carbon nanotubes on the thermal properties of erythritol as phase change materials. Energy Convers. Manag. 57, 41-48 (2018).

22. Li, M., Chen, M., Wub, Z. \& Liu, J. Carbon nanotube grafted with polyalcohol and its influence on the thermal conductivity of phase change material. Energy Convers. Manag. 83, 325-329 (2014).

23. Lee, R.-S., Chen, W.-H. \& Lin, J.-H. Polymer-grafted multi-walled carbon nanotubes through surface-initiated ring-opening polymerization and click reaction. Polymer 52(10), 2180-2188 (2011).

24. Yang, L. et al. Thermal reliability of typical fatty acids as phase change materials based on 10,000 accelerated thermal cycles. Sustain. Cities Soc. 46, 101380 (2019).

25. Song, S., Dong, L., Chen, S., Xie, H. \& Xiong, C. Stearic-capric acid eutectic/activated attapulgiate composite as form-stable phase change material for thermal energy storage. Energy Convers. Manag. 81, 306-311 (2014).

26. Mu, B. \& Li, M. Synthesis of novel form-stable composite phase change materials with modified graphene aerogel for solar energy conversion and storage. Sol. Energy Mater. Sol. Cells 191, 466-475 (2019).

27. Lin, Y., Jia, Y., Alva, G. \& Fang, G. Review on thermal conductivity enhancement, thermal properties and applications of phase change materials in thermal energy storage. Renew. Sustain. Energy Rev. 82, 2730-2742 (2018).

28. Tang, J.et al. 1-octadecanol@hierarchical porous polymer composite as a novel shape-stability phase change material for latent heat thermal energy storage. Appl. Energy 187, 514-522 (2017).

29. Tu, J. et al. Latent heat and thermal conductivity enhancements in polyethylene glycol/polyethylene glycol-grafted graphene oxide composites. Adv. Comp. Hybrid Mater. 2(3), 471-480 (2019).

30. Kumar, S., Alam, M. \& Murthy, J. Effect of percolation on thermal transport in nanotube composites. Appl. Phys. Lett. 90, 104105104113 (2007).

31. Shen, X., Wang, Z., Wu, Y., Liu, X. \& Kim, J. K. Effect of functionalization on thermal conductivities of graphene/epoxy composites. Carbon 108, 412-422 (2016).

32. Yang, X. et al. A review on thermally conductive polymeric composites: Classification, measurement, model and equations, mechanism and fabrication methods. Adv. Compos. Hybrid Mater. 1, 207-230 (2018).

33. Mehra, N. et al. Thermal transport in polymeric materials and across composite interfaces. Appl. Mater. Today 12, 92-130 (2018).

34. Huang, X., Alva, G., Liu, L. \& Fang, G. Microstructure and thermal properties of cetyl alcohol/high density polyethylene composite phase change materials with carbon fiber as shape-stabilized thermal storage materials. Appl. Energy 200, 19-27 (2017).

35. Tang, Y., Lin, Y., Jia, Y. \& Fang, G. Improved thermal properties of stearyl alcohol/high density polyethylene/expanded graphite composite phase change materials for building thermal energy storage. Energy Build. 153, 41-49 (2017).

36. Wang, X., Cheng, X., Li, Y., Li, G. \& Xu, J. Self-assembly of three-dimensional 1-octadecanol/graphene thermal storage materials. Sol. Energy 179, 128-134 (2019).

\title{
Acknowledgements
}

The authors (Amir Al-Ahmed, Ahmet Sarı and M.A.J. Mazumder) thankfully acknowledge the Deanship of Scientific Research (DSR) of King Fahd University of Petroleum \& Minerals (KFUPM), Saudi Arabia for funding, through Internal Project \# IN161025.

\section{Author contributions}

A.A.A, A.S. and M.A.J.M designed and supervised the work. A.A.A, and M.A.J.M. and I. carried out synthesis and performed FTIR, XRD analysis, A.S, G.H, and F.A.A.S. performed thermal and SEM analysis. All authors analyzed and interpreted the data. All authors discussed the data and agreed to submit the manuscript.

\section{Competing interests}

The authors declare no competing interests.

\section{Additional information}

Correspondence and requests for materials should be addressed to A.A.-A. or I.

Reprints and permissions information is available at www.nature.com/reprints.

Publisher's note Springer Nature remains neutral with regard to jurisdictional claims in published maps and institutional affiliations.

\begin{abstract}
Open Access This article is licensed under a Creative Commons Attribution 4.0 International License, which permits use, sharing, adaptation, distribution and reproduction in any medium or format, as long as you give appropriate credit to the original author(s) and the source, provide a link to the Creative Commons licence, and indicate if changes were made. The images or other third party material in this article are included in the article's Creative Commons licence, unless indicated otherwise in a credit line to the material. If material is not included in the article's Creative Commons licence and your intended use is not permitted by statutory regulation or exceeds the permitted use, you will need to obtain permission directly from the copyright holder. To view a copy of this licence, visit http://creativecommons.org/licenses/by/4.0/.
\end{abstract}

(C) The Author(s) 2020 